Argonne

ANL-20/75

\title{
Modifications to the Bubble Experiment and Preparation for Additional Irradiations
}

Chemical \& Fuel Cycle Technologies Division 


\begin{abstract}
About Argonne National Laboratory
Argonne is a U.S. Department of Energy laboratory managed by UChicago Argonne, LLC under contract DE-AC02-06CH11357. The Laboratory's main facility is outside Chicago,

at 9700 South Cass Avenue, Lemont, Illinois 60439. For information about Argonne

and its pioneering science and technology programs, see www.anl.gov.
\end{abstract}

\title{
DOCUMENT AVAILABILITY
}

Online Access: U.S. Department of Energy (DOE) reports produced after 1991 and a growing number of pre-1991 documents are available free at OSTI.GOV (http://www.osti.gov/),

a service of the US Dept. of Energy's Office of Scientific and Technical Information.

Reports not in digital format may be purchased by the public from the National Technical Information Service (NTIS):

U.S. Department of Commerce

National Technical Information Service

5301 Shawnee Road

Alexandria, VA 22312

www.ntis.gov

Phone: (800) 553-NTIS (6847) or (703) 605-6000

Fax: (703) 605-6900

Email: orders@ntis.gov

Reports not in digital format are available to DOE and DOE contractors from the Office of Scientific and Technical Information (OSTI):

U.S. Department of Energy

Office of Scientific and Technical Information

P.O. Box 62

Oak Ridge, TN 37831-0062

www.osti.gov

Phone: (865) 576-8401

Fax: (865) 576-5728

Email: reports@osti.gov

\footnotetext{
Disclaimer

This report was prepared as an account of work sponsored by an agency of the United States Government. Neither the United States Government nor any agency thereof, nor UChicago Argonne, LLC, nor any of their employees or officers, makes any warranty, express or implied, or assumes any legal liability or responsibility for the accuracy, completeness, or usefulness of any information, apparatus, product, or process disclosed, or represents that its use would not infringe privately owned rights. Reference herein to any specific commercial product, process, or service by trade name, trademark, manufacturer, or otherwise, does not necessarily constitute or imply its endorsement, recommendation, or favoring by the United States Government or any agency thereof. The views and opinions of document authors expressed herein do not necessarily state or reflect those of the United States Government or any agency thereof, Argonne National Laboratory, or UChicago Argonne, LLC.
} 
ANL-20/75

\section{Modifications to the Bubble Experiment and Preparation for Additional Irradiations}

by

James L. Bailey ${ }^{1}$, Ronald T. Kmak¹, Sergey D. Chemerisov ${ }^{1}$, James P. Byrnes ${ }^{2}$, and Peter Tkac ${ }^{2}$ ${ }^{1}$ Experimental Operations \& Facilities Division, Argonne National Laboratory

${ }^{2}$ Chemical \& Fuel Cycle Technologies Division, Argonne National Laboratory

October 2020 



\section{CONTENTS}

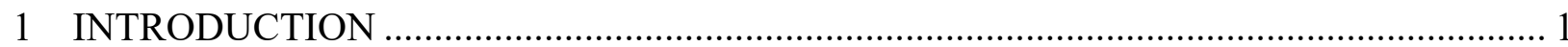

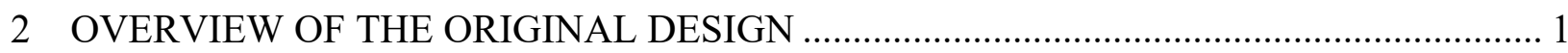

3 OVERVIEW OF MAJOR ANALYSES PERFORMED FOR ORIGINAL DESIGN …........... 3

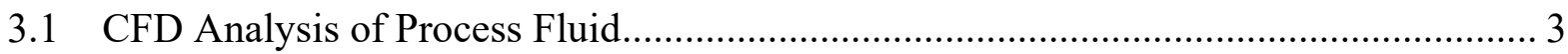

3.2 Thermal/Stress Analysis of Beam Windows ................................................................ 4

3.3 Types of Calculations Performed on Original Design.................................................. 5

4 MODIFICATIONS TO THE ORIGINAL EXPERIMENT SETUP ……………….............. 5

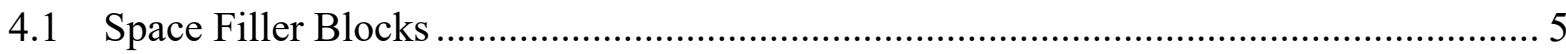

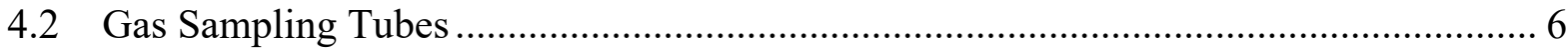

4.3 Revised Thermocouples and Supports.................................................................... 7

5 PREPARATION OF DEPLETED URANIUM SOLUTION …………………….................. 7

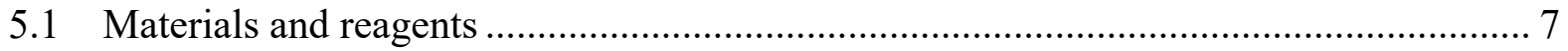

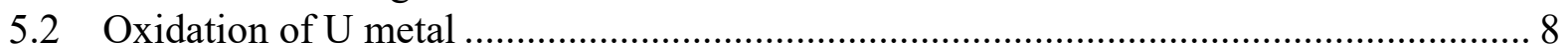

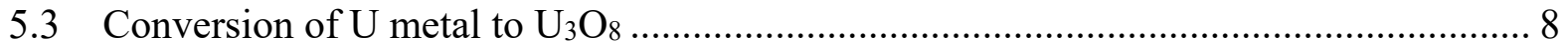

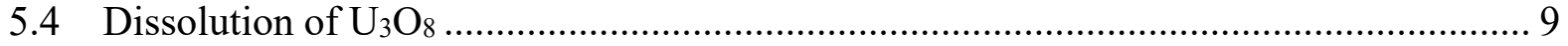

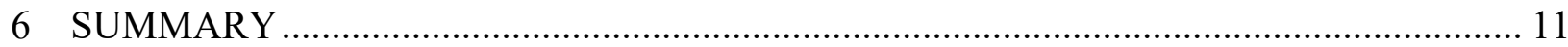

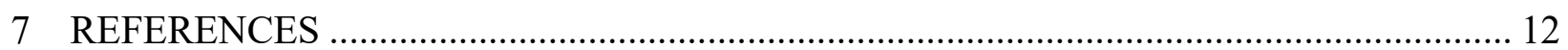

\section{FIGURES}

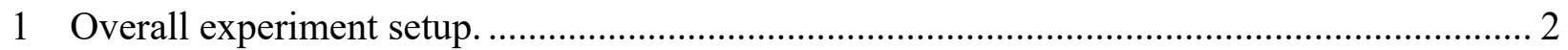

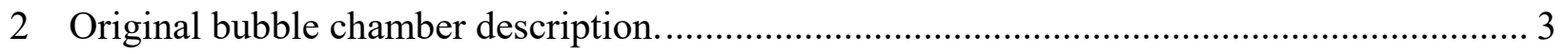

3 CFD results for temperature and velocity in process fluid. .................................................. 4

4 Stress analysis results for beam windows....................................................................... 5

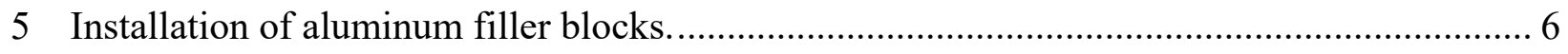

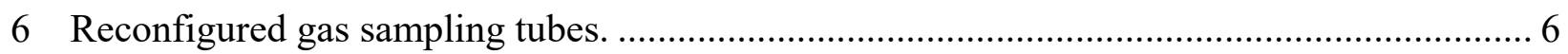

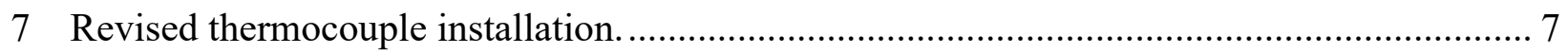

8 DU plate used for preparation of uranyl sulfate solution........................................................ 8 


\section{FIGURES (CONT.)}

9 Bottom of the dissolution apparatus (left); top of the apparatus (right), with the thermocouple connections and condenser. ................................................................. 10

10 Conversion of $\mathrm{U}_{3} \mathrm{O}_{8}$ (left) into uranyl sulfate solution (right) during the dissolution of $\mathrm{U}_{3} \mathrm{O}_{8}$ with hydrogen peroxide and sulfuric acid as described by eqs. 1 and 2 . 11

TABLE

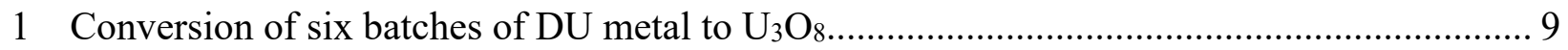




\section{INTRODUCTION}

SHINE Medical Technologies is planning to use neutron-induced fission in a subcritical low-enriched-uranium uranyl sulfate target solution for production of ${ }^{99} \mathrm{Mo}[1,2]$. During this operation, the solution will undergo self-heating due to fissioning of the uranium, radiolytic decomposition of the water, and circulation due to thermal gradients generated in the solution, and will be cooled by cooling tubes running through the annulus and from cooling outside the annulus. Because the formation of the radiolysis-induced bubbles $\left(\mathrm{H}_{2}\right.$ and $\left.\mathrm{O}_{2}\right)$ and their size and dynamics will impact the operational parameters of the liquid target, an understanding of bubble behavior is critical for the ability to predict the behavior of the target solution during this operation. It is also important to be able to predict the thermal gradients and the circulation in the vessel. Researchers at Argonne National Laboratory have designed an experimental setup to study radiolytic gas formation in uranyl sulfate under direct electron beam irradiation [3] and have conducted initial experiments [4]. Results of those experiments provided invaluable information on thermal hydraulic behavior of the solution and some information on bubble formation and behavior, but those initial experiments fell short in the measurements of the gas generation rates and bubble behavior.

To address the shortcomings of the original experiment, the irradiation setup was modified to improve our abilities to measure gas generation rates and measure the temperature distribution in the solution with better precision. Modifications to the experimental setup and preparation for the irradiations are described below.

\section{OVERVIEW OF THE ORIGINAL DESIGN}

The original design of the bubble chamber assembly is shown in Figure 1. The experimental setup for direct electron irradiation consists of the beamline and beam optics, the water-cooled solution chamber, a camera for bubble detection, and the cooling system. 


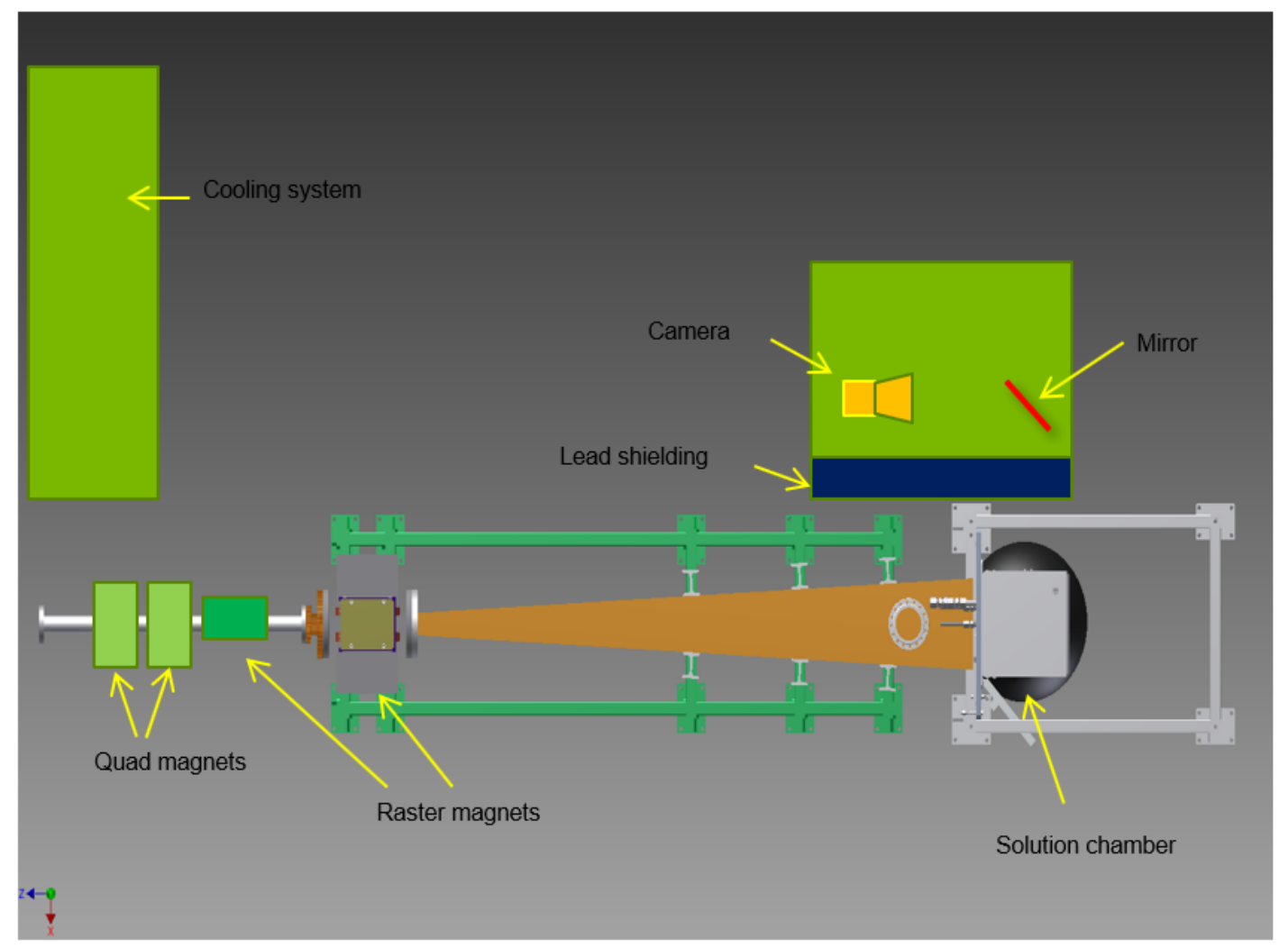

\section{FIGURE 1 Overall experiment setup.}

Details of the chamber assembly are shown in Figure 2. The assembly contains a rectangular sealed vessel that contains the uranyl sulfate solution. The electron beam enters the vessel through a beam window located at the left-side wall. The outer surface of this wall interfaces with the raster vacuum chamber in the beamline. The beam window is double-walled to allow for coolant flow between the walls. The two side walls have quartz windows for visual inspection of the solution during irradiation. The right-side wall and the bottom wall are doubled-walled to also provide for coolant flow. In addition, there is a drain-and-fill tube connection in the bottom wall of the vessel. The vessel's top plate contains penetrations for thermocouple assemblies and coolant center tube, and additional penetrations for venting and purging. The chamber is welded all-stainless-steel construction.

A secondary containment is installed around the solution chamber to mitigate a containment failure of the primary vessel. The side walls have quartz windows to allow observation of the bubbles in the solution. These windows are aligned with the primary windows. A 2-in. drain is located in the bottom of the chamber and is connected to an external holding tank. The secondary containment is welded aluminum construction. 


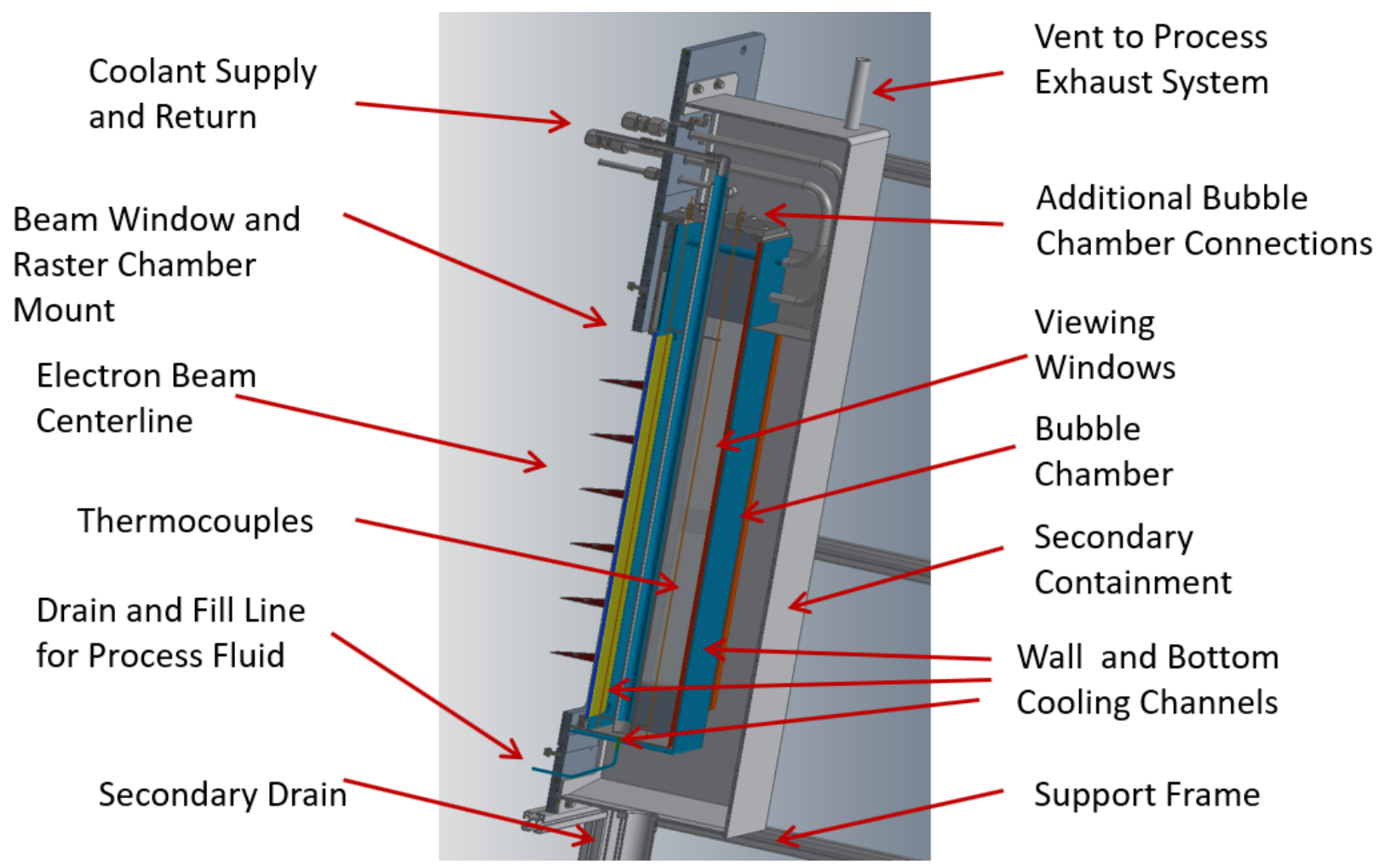

FIGURE 2 Original bubble chamber description.

\section{OVERVIEW OF MAJOR ANALYSES PERFORMED FOR ORIGINAL DESIGN}

\subsection{CFD ANALYSIS OF PROCESS FLUID}

A rectangular fluid volume with a $10-\mathrm{kW}$ uniform heat generation due to beam heating was assumed. The boundaries at the left, right and bottom walls (walls that are force-convectioncooled) were assumed to be at a constant near-ambient temperature (i.e., the coolant temperature). The two side walls (walls with no cooling and with viewing windows) were assumed to be insulated. Also, the free surface at the top of the process fluid was assumed to be insulated. The process fluid properties were assumed to be that of water. The temperature and velocity profiles through the center of the chamber are shown in Figure 3. The maximum temperature in the fluid is $81^{\circ} \mathrm{C}$ at the $10-\mathrm{kW}$ heat generation rate. Essentially, the analysis indicates that a heat generation significantly above $10 \mathrm{~kW}$ would result in boiling of the fluid. The velocity profile shows the weak natural convection flow within the fluid. The resulting high thermal convective resistance inherently limits the maximum beam power for irradiation of the fluid. 


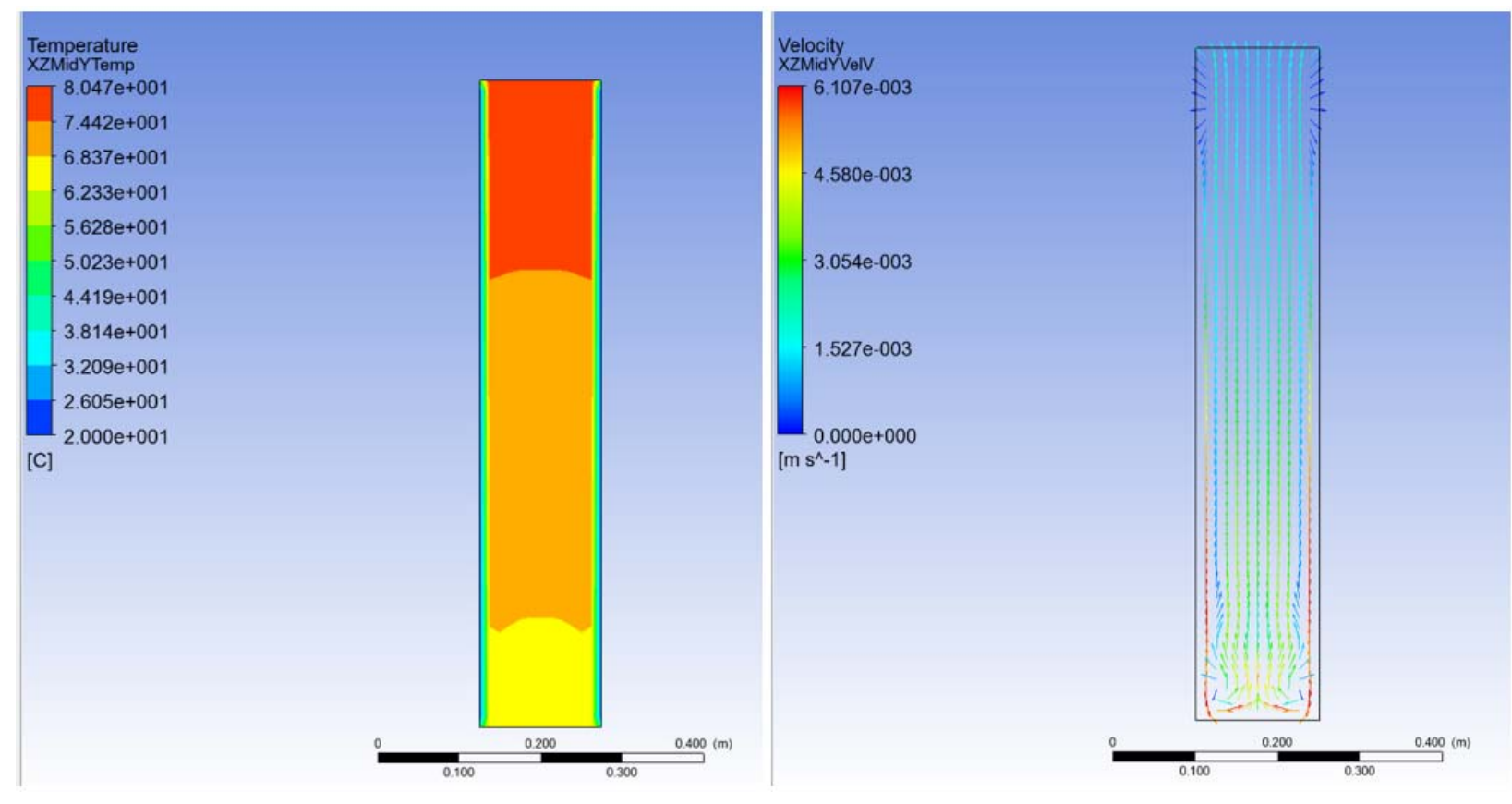

FIGURE 3 CFD results for temperature and velocity in process fluid.

\subsection{THERMAL/STRESS ANALYSIS OF BEAM WINDOWS}

The large size of the water-cooled beam window and our desire to minimize material thicknesses, which cause beam losses, represented a significant engineering challenge. The solution we found included a curved window to resist the buckling. Static structural analysis of the beam window separating the electron beam and the process fluid was performed using an ANSYS computer model. The window uses a double-wall design to allow coolant flow, as well. The window design employs a 15-in. cylindrical radius to maintain the necessary rigidity while minimizing material thickness. The side towards the vacuum chamber must resist a pressure differential of 24.7 psi.

Initial results from the analysis showed that the main concern in the window design would be the ability to provide sufficient rigidity to resist buckling. A linear buckling analysis based on the static structural analysis was performed, and the design was adjusted to withstand buckling from a differential pressure of 50 psi. However, during leak testing of the window assembly, a tendency to buckle was observed, probably as a result of deformation of the windows during fabrication, which necessitated supplemental stiffening with 6 ribs. The real curvature of the window was measured and each rib was cut to precisely reflect this curvature. The ribs were welded to the vacuum side of the window assembly. Subsequent testing of the window assembly showed no buckling. 


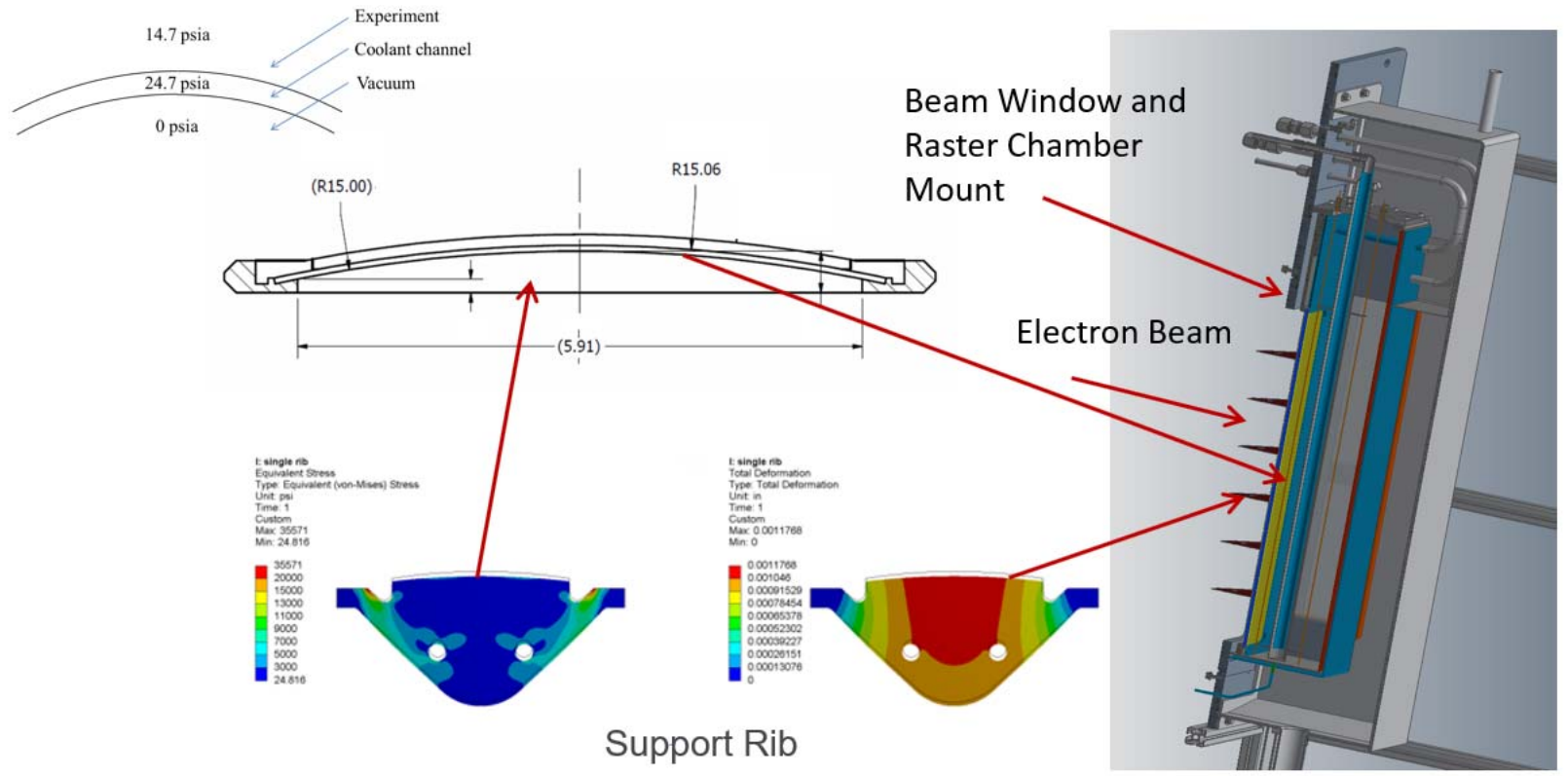

FIGURE 4 Stress analysis results for beam windows.

\subsection{TYPES OF CALCULATIONS PERFORMED ON ORIGINAL DESIGN}

Several calculations, including thermal, hydraulic and stress calculations, were performed for the original design using classical correlations and the MathCad calculation program.

\section{MODIFICATIONS TO THE ORIGINAL EXPERIMENT SETUP}

\subsection{SPACE FILLER BLOCKS}

As shown in Figure 5, several aluminum blocks were installed at the top of the process fluid chamber. The purpose of these blocks is to reduce the gas void at the top in order to avoid diluting the gas sample that is generated in the process fluid and collects at the top. A thin stainless steel plate was added at the bottom of the blocks, just above the process fluid surface, to protect the aluminum from the corrosive process fluid. 


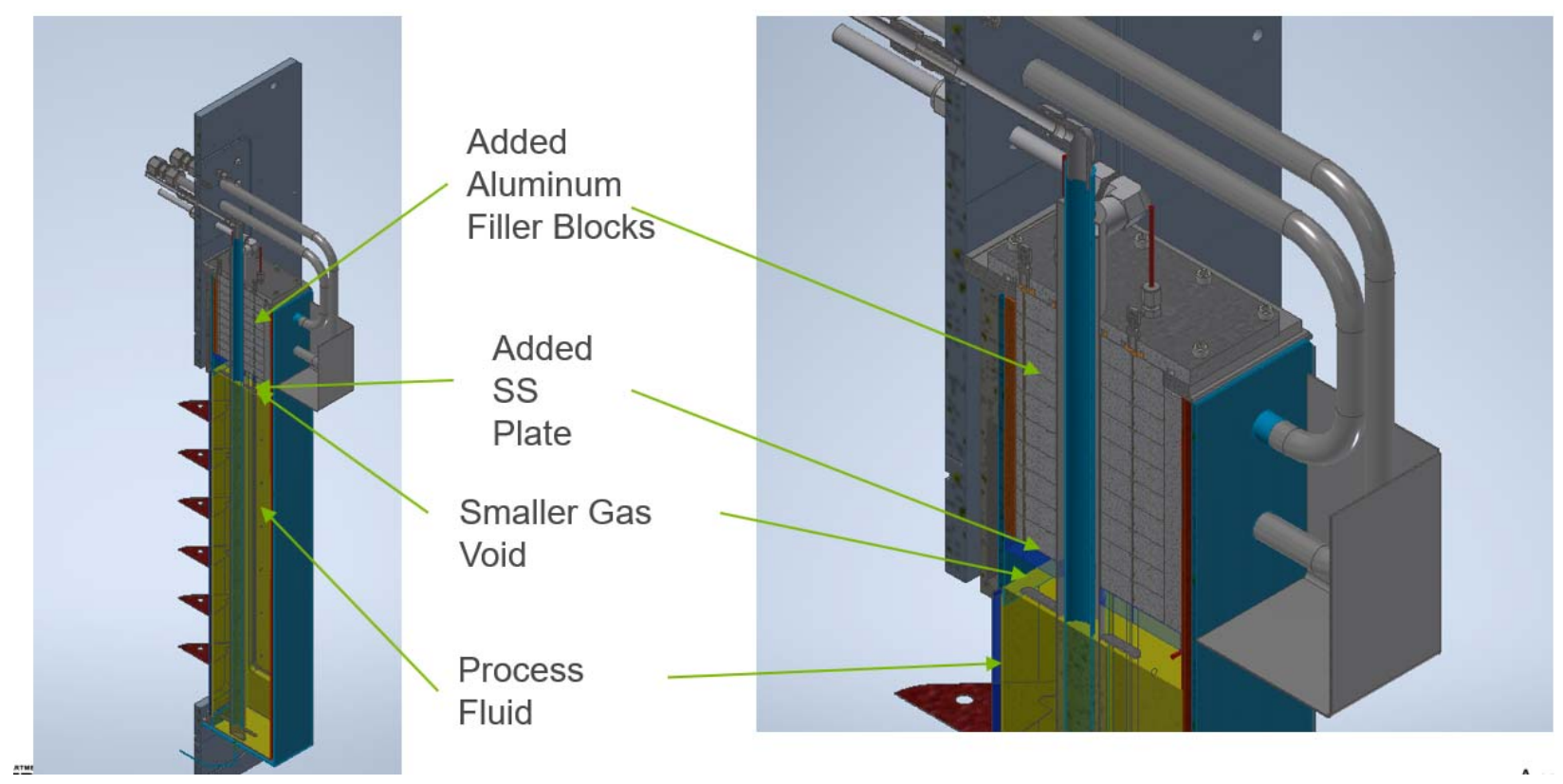

FIGURE 5 Installation of aluminum filler blocks.

\subsection{GAS SAMPLING TUBES}

As shown in Figure 6, gas sampling tube extensions were added to provide gas flow in and out from the gas void above the process fluid. The tube entrance and exit were positioned to ensure mixing of the gas sample in the void.

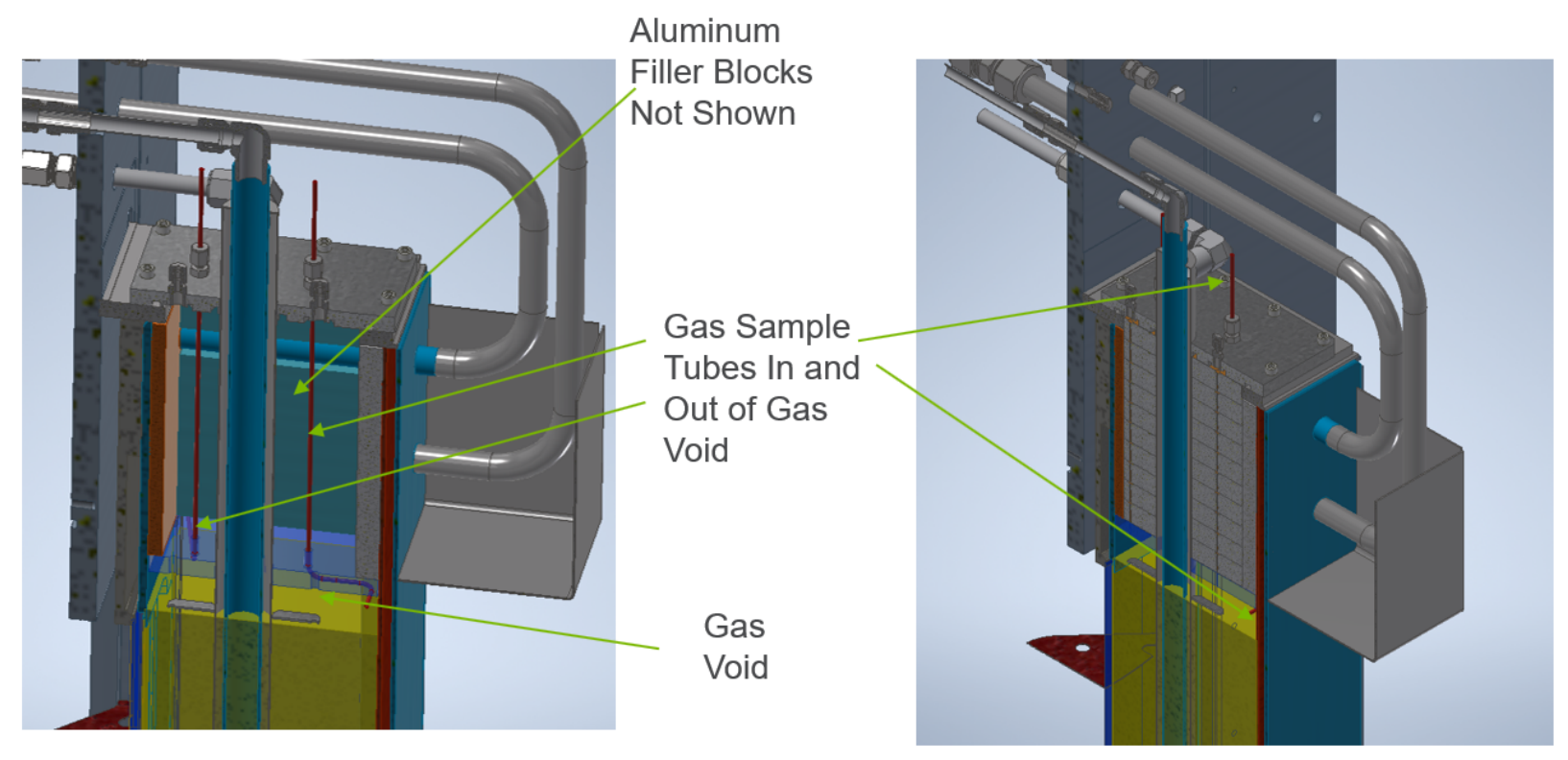

FIGURE 6 Reconfigured gas sampling tubes. 


\subsection{REVISED THERMOCOUPLES AND SUPPORTS}

As shown in Figure 7, the original 0.04-in.-OD thermocouples were replaced with 0.02 -in.-OD thermocouples. It was found in the original experiment that considerable selfheating of the 0.04-in.-OD thermocouples occurred, which caused inaccurate measurements of the fluid measurements. The revised design incorporates a smaller-OD thermocouple with the junction pointing parallel to the electron beam. It is expected that this configuration will provide a more accurate measurement of the fluid temperature. As a result of this configuration, thermocouple tube supports are required to provide rigidity to the assembly.
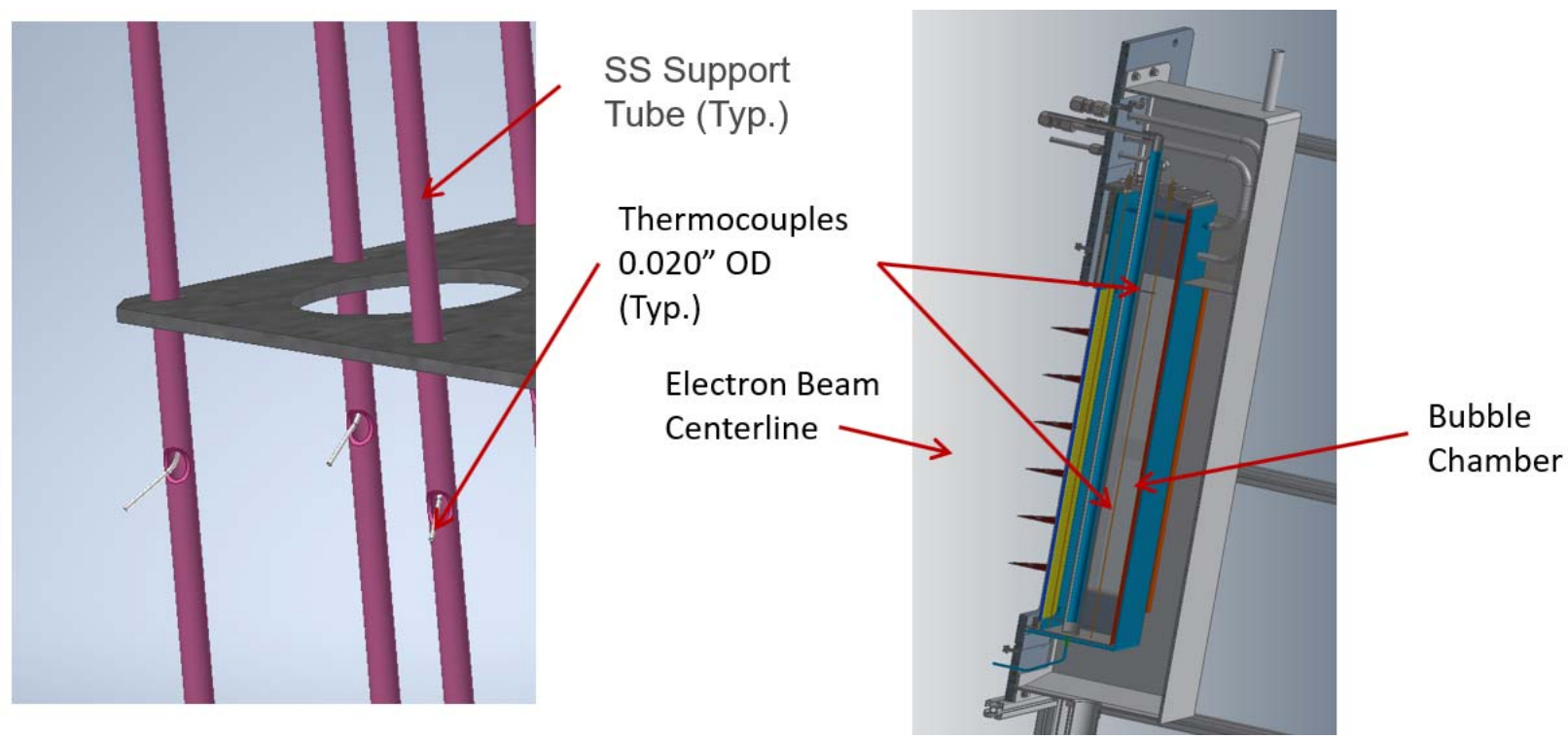

FIGURE 7 Revised thermocouple installation.

\section{PREPARATION OF DEPLETED URANIUM SOLUTION}

The desired $\mathrm{U}$ concentration for the Bubble experiment is $\sim 200 \mathrm{~g} / \mathrm{L}$, which is higher compared to previous experiments performed in 2015 with $\mathrm{U}$ concentration at $\sim 138 \mathrm{~g} / \mathrm{L}[3,4]$. To adjust the concentration to $200 \mathrm{~g} / \mathrm{L}$ and utilize $\mathrm{U}$ solution from the previous experiment, an additional amount of uranyl sulfate needed to be prepared.

\subsection{MATERIALS AND REAGENTS}

Sulfuric acid was purchased from Sigma-Aldrich (Part \# 320501-2.5L). 30\% hydrogen peroxide was purchased from Fisher Chemical (Part \# H325-500). A depleted uranium (DU) plate used for preparation of uranyl sulfate solution is depicted in Figure 8. 


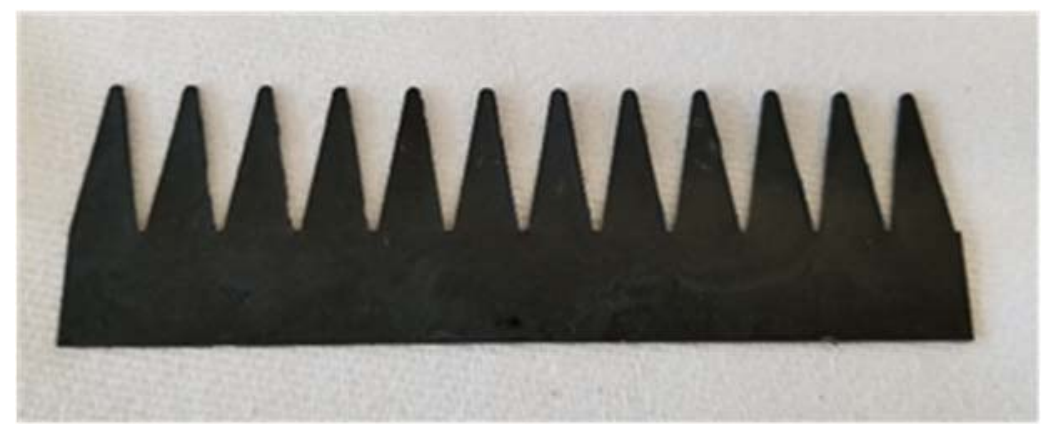

FIGURE 8 DU plate used for preparation of uranyl sulfate solution.

\subsection{OXIDATION OF U METAL}

Typically, about 200- to 500-g batches of DU plates were converted to $\mathrm{U}_{3} \mathrm{O}_{8}$ by heating. The $\mathrm{U}$ was placed in a quartz beaker and baked at ramping temperatures until $820^{\circ} \mathrm{C}$ was reached, and held for 4 hours. The produced $\mathrm{U}_{3} \mathrm{O}_{8}$ was then converted to uranyl sulfate solution by addition of hydrogen peroxide and sulfuric acid as follows:

$$
\begin{gathered}
\mathrm{U}_{3} \mathrm{O}_{8}+4 \mathrm{H}_{2} \mathrm{O}_{2}=3 \mathrm{UO}_{2}\left(\mathrm{O}_{2}\right)+4 \mathrm{H}_{2} \mathrm{O} \\
\mathrm{UO}_{2}\left(\mathrm{O}_{2}\right)+\mathrm{H}_{2} \mathrm{SO}_{4}=\mathrm{UO}_{2} \mathrm{SO}_{4}+\mathrm{H}_{2} \mathrm{O}+1 / 2 \mathrm{O}_{2}
\end{gathered}
$$

\subsection{CONVERSION OF U METAL TO $\mathrm{U}_{3} \mathrm{O}_{8}$}

About $15.5 \mathrm{~L}$ of uranyl sulfate solution at a concentration of $134.6 \mathrm{~g}-\mathrm{U} / \mathrm{L}$ was recovered from the previous Bubble experiment [4]. To adjust the concentration of $U$ to $200 \mathrm{~g} / \mathrm{L}$ and the volume to $20 \mathrm{~L}$, additional uranyl sulfate solution at a higher $\mathrm{U}$ concentration was needed. It was determined that this amount required conversion of $\sim 2 \mathrm{~kg}$ of uranium metal into $\mathrm{U}_{3} \mathrm{O}_{8}$, followed by dissolution to form uranyl sulfate solution. Six batches of DU plates were converted to $\mathrm{U}_{3} \mathrm{O}_{8}$ to provide $\sim 2.6 \mathrm{~kg}$ of $\mathrm{U}_{3} \mathrm{O}_{8}$ material (Table 1). 
TABLE 1 Conversion of six batches of DU metal to $\mathrm{U}_{3} \mathrm{O}_{8}$

\begin{tabular}{cccc}
\hline Batch \# & $\begin{array}{c}\text { DU metal, } \\
\mathrm{g}\end{array}$ & $\begin{array}{c}\mathrm{U}_{3} \mathrm{O}_{8} \text { theoretical } \\
\text { mass, g, after } \\
\text { conversion }\end{array}$ & $\begin{array}{c}\text { Actual } \mathrm{U}_{3} \mathrm{O}_{8} \text { mass, } \\
\mathrm{g}\end{array}$ \\
\hline & & & \\
1 & 222.4 & 262.27 & 262.1 \\
2 & 321.9 & 379.60 & 378.5 \\
3 & 356.1 & 419.94 & 419.4 \\
4 & 349.8 & 412.51 & 411.8 \\
5 & 410.4 & 483.97 & 483.2 \\
6 & 531.5 & 626.78 & 626 \\
\hline Total & 2192.1 & 2585.1 & 2581 \\
\hline
\end{tabular}

The $\mathrm{U}_{3} \mathrm{O}_{8}$ material was then combined and divided into eight batches, each containing $\sim 307 \mathrm{~g}$ of $\mathrm{U}_{3} \mathrm{O}_{8}$. Each batch of $\mathrm{U}_{3} \mathrm{O}_{8}$ was then combined with $30 \%$ hydrogen peroxide and $98 \%$ $\mathrm{H}_{2} \mathrm{SO}_{4}$ for dissolution to make uranyl sulfate solution. A total of $2.085 \mathrm{~kg}$ of DU metal was converted to uranyl sulfate solution.

\subsection{DISSOLUTION OF $\mathrm{U}_{3} \mathrm{O}_{8}$}

Dissolution of uranium oxide was performed in a large-scale dissolution apparatus shown in Figure 9, as discussed in more detail in a previous report [5]. 


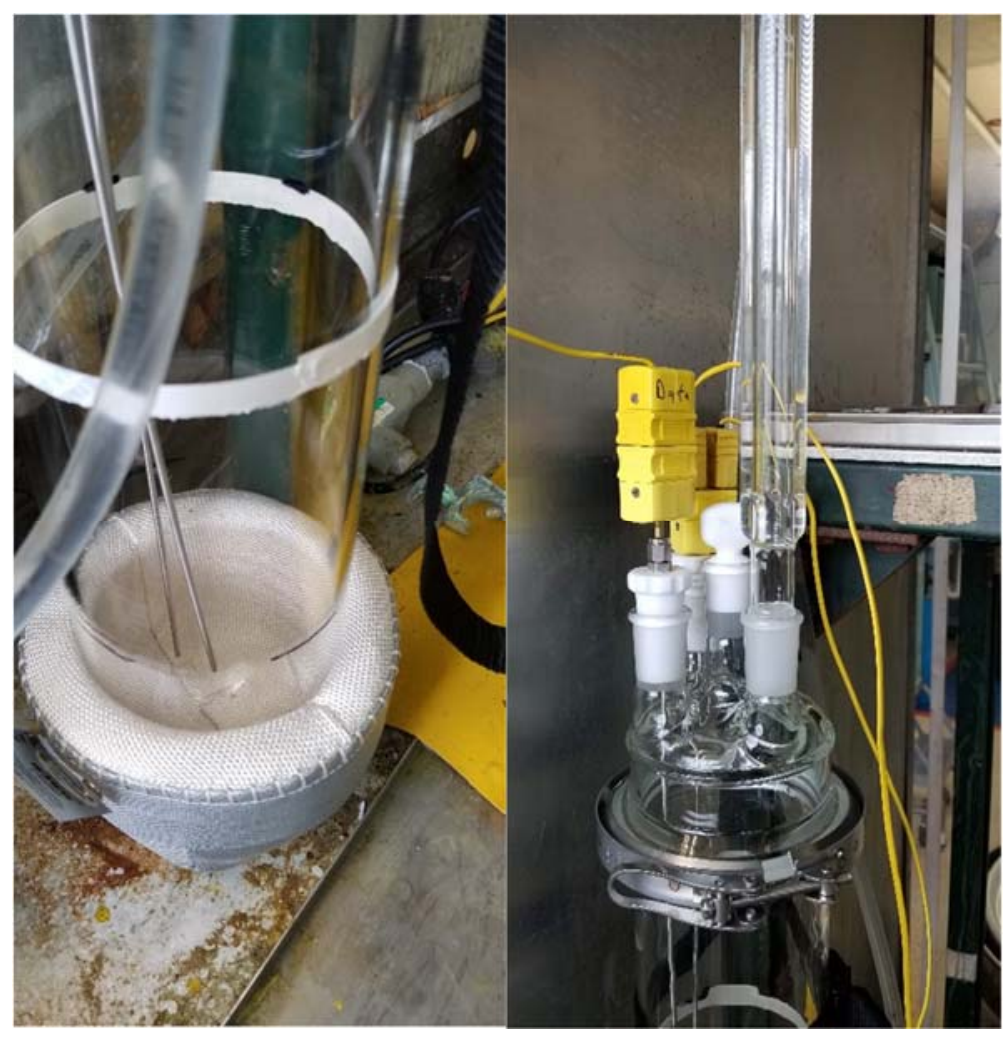

FIGURE 9 Bottom of the dissolution apparatus (left); top of the apparatus (right), with the thermocouple connections and condenser.

Briefly, before the dissolution of $\sim 307$-g batches of $\mathrm{U}_{3} \mathrm{O}_{8}$, the water chiller connected to the condenser on top of the dissolution vessel (Figure 10) was set to $5^{\circ} \mathrm{C}$. Then, hydrogen peroxide was added, followed by the addition of the desired amount of concentrated sulfuric acid. Shortly after adding the reagents, the temperature increased to $\sim 100^{\circ} \mathrm{C}$, and it was controlled to stay at $\sim 95-100^{\circ} \mathrm{C}$ using a heating mantle (Figure 10) and a J-KEM controller. As the dissolution reaction progressed, the color of the suspension changed from black to gray to yellow, and yellow precipitate formed. Upon further heating, and decomposition of excess hydrogen peroxide, the yellow precipitate turned into a clear yellow uranyl sulfate solution (Figure 10). 


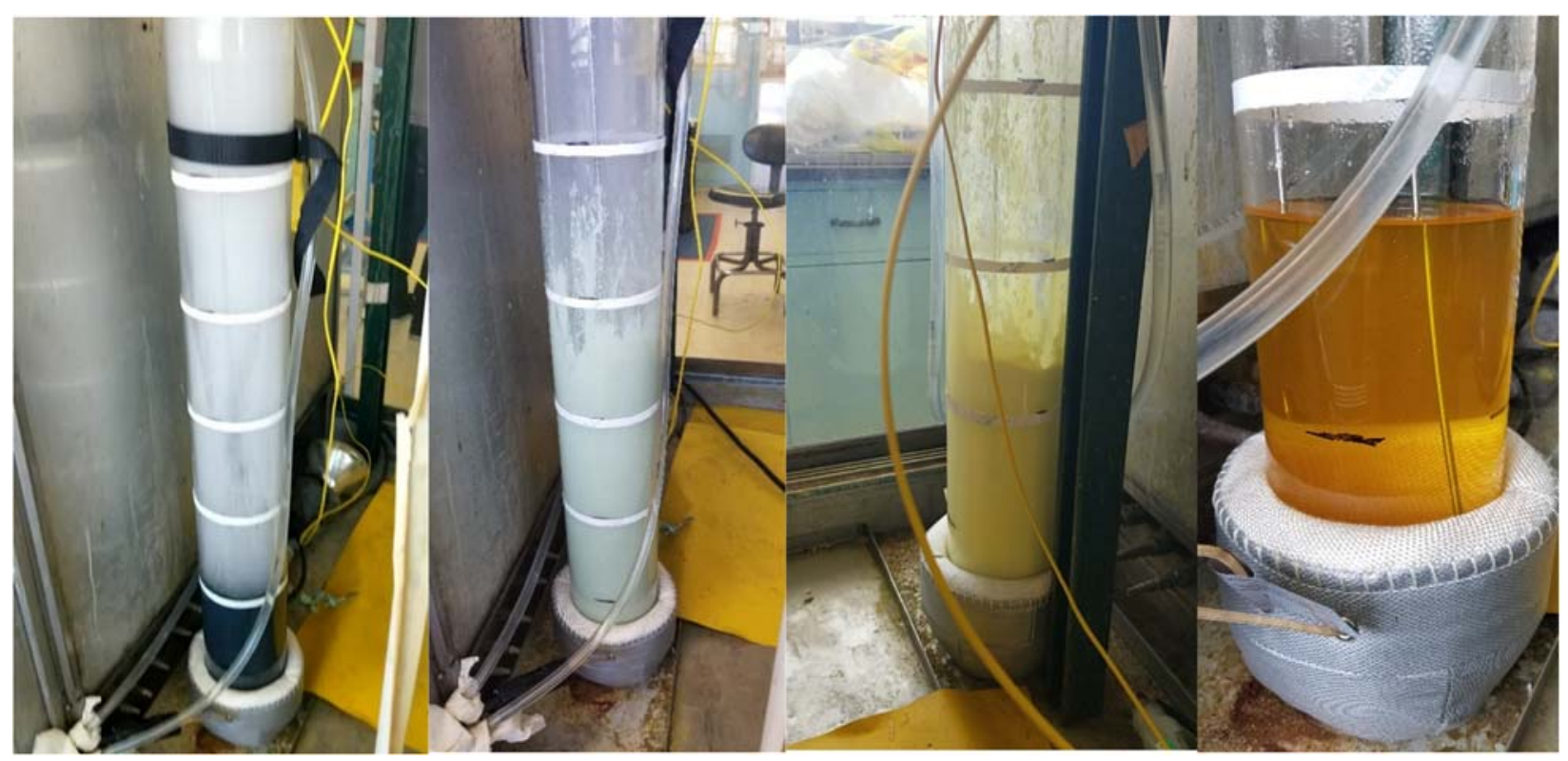

FIGURE 10 Conversion of $\mathrm{U}_{3} \mathrm{O}_{8}$ (left) into uranyl sulfate solution (right) during the dissolution of $\mathrm{U}_{3} \mathrm{O}_{8}$ with hydrogen peroxide and sulfuric acid as described by eqs. 1 and 2 .

Uranyl sulfate solutions obtained from eight dissolution batches were combined and submitted for inductively coupled plasma - optical emission spectrometry. The U concentration of the combined uranyl sulfate solution was determined to be $359 \mathrm{~g} / \mathrm{L}$ and $\mathrm{pH}=1.65$. To increase the uranium concentration, the solution can be further concentrated by evaporation and the $\mathrm{pH}$ adjusted by addition of $\mathrm{H}_{2} \mathrm{SO} 4$ as needed.

\section{SUMMARY}

The original Bubble experiment was designed in 2014 and experiments were performed in 2014 and 2015. The experiment was then disassembled and stored for future use. The original bubble chamber is ready to be removed from storage and modified. The design modifications have been completed and reviewed, with comments incorporated. Except for minor hardware, all parts required for the modifications have been ordered and received. The bubble chamber is ready for modification work and installation into the electron beamline, and the revised experiments will then be performed. To accommodate the change in concentration of the uranyl sulfate solution from $138 \mathrm{~g}-\mathrm{U} / \mathrm{L}$ to $200 \mathrm{~g}-\mathrm{U} / \mathrm{L}$, an additional $2.2 \mathrm{~kg}$ of DU metal was converted to $\mathrm{U}_{3} \mathrm{O}_{8}$. This $\mathrm{U}_{3} \mathrm{O}_{8}$ was then dissolved to form uranyl sulfate solution, which is ready to be used for concentration adjustment. 


\section{REFERENCES}

[1] K.M. Pitas et al., "SHINE: Technology and Progress," Proceedings of the Mo-99 2013 Topical Meeting on Molybdenum-99 Technological Development, April 1-5, 2013, Chicago, IL, http://mo99.ne.anl.gov/2013/pdfs/Mo99\%202013\%20Web\%20Papers/ S6P2_Pitas_Paper.pdf.

[2] K. Pitas, "The SHINE Path to a Reliable Domestic Supply of Mo-99," Proceedings of the Mo-99 2014 Topical Meeting on Molybdenum-99 Technological Development, June 24-27, 2014, Washington, DC, http://mo99.ne.anl.gov/2014/pdfs/presentations/ S10P2\%20Presentation\%20Pitas.pdf.

[3] S. Chemerisov et al., "Experimental Setup for Direct Electron Irradiation of the Uranyl Sulfate Solution: Bubble Formation and Thermal Studies," Proceedings of the Mo-99 2014 Topical Meeting on Molybdenum-99 Technology Development, June 24-27, 2014.

[4] S. Chemerisov et al., Experimental Results for Direct Electron Irradiation of a Uranyl Sulfate Solution: Bubble Formation and Thermal Hydraulics Studies, Technical Report ANL/NE-15/19, Argonne National Laboratory, 2015.

[5] T. Brossard, J. Byrnes, and P. Tkac, Conversion of Uranium Metal to Uranyl Sulfate Solution, Technical Report ANL-20/18, Argonne National Laboratory, 2020. 



\section{Argonne}

\section{Chemical \& Fuel Cycle Technologies Division}

Argonne National Laboratory

9700 South Cass Avenue, Bldg. 205

Lemont, IL 60439-4832

www.anl.gov 